\title{
Intense Sweeteners and the Control of Appetite
}

\author{
Adam Drewnowski, Ph.D.
}

The sensation of sweet taste without calories has been said to increase appetite and promote food consumption. Regular use of intense sweeteners might therefore lead to a paradoxical weight gain. These alarmist reports have not been confirmed by recent experimental data. There is no evidence that the addition of an intense sweetener to a plain stimulus promotes appetite or results in increased food consumption during some later meal. While replacing sugars with intense sweeteners (with attendant decrease in energy) has been said to result in energy compensation, published studies have variously reported perfect compensation, partial compensation, or no compensation at all, depending on the conditions used. Longer-term studies are needed to assess chronic effects of intense sweeteners on dietary compliance and the control of body weight.

Repeated claims that intense sweeteners may increase appetite and therefore food consumption ${ }^{1,2}$ have led some consumers to question the usefulness of low-energy foods in weight control. In particular, the popular press has propagated the notion that regular use of intense sweeteners, such as aspartame or saccharin, provides no benefits in weight control and can actually lead to increased food intake and a paradoxical weight gain.

Previous treatments of this complex issue ${ }^{3}$ have been marked by some disagreements as to the precise effects of intense sweeteners on appetite and satiety. ${ }^{4.5}$ However, recent studies ${ }^{6-9}$ on the effects of aspartame on hunger, food intake, and body weight should bring this long-standing controversy to a close.

\section{The Sweetener "Paradox"}

Claims that intense sweeteners promote hunger and increase food consumption were largely based on

Dr. Drewnowski is the director of the Program in Human Nutrition, School of Public Health, University of Michigan, Ann Arbor, MI 48109, USA. only two published studies. The first, a brief letter to The Lancet, ${ }^{1}$ reported that the ingestion of a sweet aspartame solution instead of plain water suppressed taste preferences for sucrose solutions (implying a reduction in appetite), but actually increased the motivation to eat, which implied an increase in food consumption.

This dissociation between reduced sweet taste preferences and increased appetite was described as "paradoxical." The authors suggested that such ambiguous psychobiologic signals might lead to a loss of control over appetite and contribute to the development of eating disorders.' The implicit threat, made clearer in a subsequent publication, ${ }^{10}$ was that regular use of intense sweeteners might contribute to the development of bulimia nervosa in vulnerable individuals.

That same study ${ }^{1}$ reported that noncaloric aspartame solutions $(<1 \mathrm{kcal})$ suppressed appetite ratings less effectively than did caloric glucose solutions $(188 \mathrm{kcal})$, thus showing that aspartame is not an appetite suppressant and that some calories are more satiating than none. The question that might be asked at this point is whether the calorie savings realized with intense sweeteners are offset either at the next meal or at some later time. Consistent findings that elevated hunger leads to accurate caloric compensation and no net change in daily energy intakes might raise some legitimate questions regarding the efficacy of intense sweeteners promoting weight loss.

However, a second report from the same laboratory ${ }^{11}$ went considerably further in showing rebound rather than calorie compensation. The consumption of a saccharin-sweetened as opposed to plain yogurt reportedly increased hunger, promoted food intake at lunch time, and stimulated energy intake for many hours after lunch." A single small portion of saccharin-sweetened fruit yogurt $(131 \mathrm{kcal})$ was reported to stimulate food intake for more than 12 hours postingestion. That study suggested that the effects of intense sweeteners in promoting appetite and food consumption were significant, robust, and liable to extend over more than one meal. ${ }^{1}$ The 
popular interpretation of these findings was that eating diet foods could make you fat.

While the "paradoxical" effects of intense sweeteners continued to receive much attention in the popular press, numerous laboratory attempts to replicate the initial report of Blundell and Hill' ended in failure..$^{3.12}$ Most of the studies showed that the consumption of aspartame-sweetened as opposed to unsweetened beverages was associated, at least in the short term, with unchanged hunger or motivation to eat. ${ }^{3,12}$ Apart from one report" that saccharin-sweetened yogurt increased food intakes, intense sweeteners had no stimulating effect on food consumption. However, such studies used a wide variety of designs and procedures, sometimes making data interpretation difficult. This review will examine recently published studies on aspartame, hunger, and food intake, and will focus on some important aspects of data collection and study design.

\section{The Preload Paradigm}

Studies on the effects of intense sweeteners on appetite and food intake were largely concerned with the extent of caloric compensation at the next meal. In the most commonly used study design, ingestion of a single sweet stimulus was shortly followed by a single test meal or snack. The time interval between stimulus preload and the next eating occasion was typically brief, most often between 30 and 60 minutes. In most cases, the sweet preload was a beverage ${ }^{13-17}$ rather than a solid food such as pudding or cereal, ${ }^{18-20}$ and the difference between the high- and the low-energy versions rarely exceeded $200 \mathrm{kcal}^{13-17}$ More recent studies ${ }^{8,9}$ employed a more powerful energy manipulation $(400 \mathrm{kcal})$, a longer time interval (2-3 hours), and three consecutive test meals: lunch, snack, and dinner. As will be seen later, the observed sweetener effects may depend on subject selection and on study design.

Some past studies have also tried to separate the potential effects of sweetness and calories. Here, Blundell and colleagues ${ }^{21}$ have made the useful distinction between the substitution and addition conditions. Briefly, the substitution of an intense sweetener for sucrose maintains sweetness, while reducing the energy value of the stimulus. Comparing aspartame-sweetened with sucrose-sweetened beverages is an example of the substitution condition.

Conversely, the addition of an intense sweetener to a plain stimulus adds sweet taste without altering its energy value. Comparing aspartame solution to plain water, or saccharin-sweetened yogurt to plain yogurt is an example of the addition condition. While examples of both manipulations can be found in the sweetener literature, ${ }^{3,12}$ few studies have in- corporated both conditions in a single experimental design.

Among the published studies, some compared aspartame-sweetened beverages only to sugar solutions, ${ }^{13.19}$ or to mineral water, ${ }^{15}$ while others employed both aspartame- and sugar-sweetened beverages in addition to plain water. $^{16,17,22}$ One study"l incorporated the addition and substitution conditions by using yogurts that were either plain, sweetened with sucrose or saccharin, or plain but supplemented with starch. Similarly, two recent studies $^{8.9}$ contrasted the effects of sweetness and calories by using preloads of yogurt-like creamy white cheese ("fromage blanc") that were either plain, sweetened with aspartame or sucrose, or sweetened with aspartame and supplemented with maltodextrin.

Uncoupling sweetness and calories can help answer two key questions. The first is whether the substitution of an intense sweetener for sucrose will lead to energy compensation, either by the next meal or at some later time. Rogers and Blundell $1^{2.11}$ have repeatedly argued that calorie savings achieved with intense sweeteners are false and likely to be offset by increased energy intake during a later meal. The second question is whether the addition of an intense sweetener to a plain stimulus will have the effect of promoting appetite and subsequent food consumption. Two unconfirmed reports $^{2,11}$ have suggested that it will.

Most studies on intense sweeteners and appetite have used hunger ratings and food intake measures as the main dependent variables. Apart from the original report of Blundell and Hill,' no study examined sweet taste preferences in addition to motivational ratings and food consumption measures. Yet the original aspartame "paradox" was critically dependent on taste data, being based on the premise that a reduction in sweet taste preferences (or negative allesthesia) invariably suggests a reduction in appetite.

Unfortunately, that premise is false. It cannot be assumed that the relationship between sweet taste preferences, appetite, and energy intakes in humans is so strong that one variable can serve as a proxy measure of another. There are too many examples to the contrary. Sweet taste preferences do not change following breakfast or lunch, ${ }^{23}$ but can be reduced by the ingestion of sweet though noncaloric beverages, ${ }^{24}$ most likely through the mechanism of sensory-specific satiety. ${ }^{25}$ Indeed, a 1972 study $^{24}$ showed that sweet taste preferences were suppressed equally by caloric glucose and noncaloric cyclamate solution, a finding analogous to that subsequently reported by Blundell and Hill.' Similarly, hunger ratings need not be a valid proxy measure of food consumption, ${ }^{26}$ so that small changes in 
hunger ratings following sweetener ingestion may be without practical significance. In some published studies, ${ }^{10}$ slight but statistically significant increases in appetite were not in fact followed by corresponding increases in food consumption.

\section{Do Intense Sweeteners Increase Appetite?}

The initial reports ${ }^{1,11}$ that adding aspartame to plain water and saccharin to plain yogurt leads to a robust increase in appetite ratings have not been replicated in later studies. ${ }^{3.12}$ No stimulation of appetite was observed for beverages, or for such foods as cereal, gelatin dessert, or creamy dessert-type white cheese, even with motivational ratings measured for up to 120 minutes postingestion. The addition of sweet taste at levels close to the hedonic optimum had no significant effect on appetite.

Other than the studies by Blundell and colleagues, only one study ${ }^{6}$ observed a transient increase in the desire to eat following the consumption of $340 \mathrm{mg}$ of aspartame in $280 \mathrm{~mL}$ of mineral water relative to an equal amount of plain water. In addition, a study ${ }^{27}$ that used different levels of aspartame in chewing gum reported an increase in subjective hunger ratings, though not in a way that was monotonically related to sweetness levels.

The effects of substituting intense sweeteners for sugar have been more difficult to interpret. While high-calorie stimuli ought to suppress hunger more effectively than low-calorie stimuli, several studies have found that replacing sucrose with aspartame (with the attendant decrease in calories) had no appreciable effect on hunger ratings. In one study of 9- and 10-year-old children, ${ }^{14}$ aspartame-sweetened soft drinks ( $3 \mathrm{kcal})$ did not lead to higher hunger ratings relative to sucrose-sweetened drinks (90 kcal) or drinks sweetened with aspartame and supplemented with a carbohydrate (Polycose [Ross Laboratories]). In another study, ${ }^{17}$ adults who consumed aspartame- or sucrose-sweetened lemonade ( $5 \mathrm{kcal}$ versus $166 \mathrm{kcal}$ ) showed no major differences in hunger ratings as measured 0,30 , and 60 minutes later. Similarly, adults who consumed a high- or a low-calorie pudding or a gelatin dessert (mean energy difference: $206 \mathrm{kcal}$ ) showed comparable ratings of hunger and the desire to eat 120 min later. ${ }^{20}$

These data suggest that subjects cannot easily distinguish between low- and high-energy versions of the same stimulus, at least for a short time postingestion. In most studies, energy manipulations were relatively small $(80-200 \mathrm{kcal})$, and the time interval was generally in the order of 30-60 minutes.

A recent study by Black et al. ${ }^{6}$ showed that the perception of hunger and satiety may be influenced more strongly by the volume of preload consumed

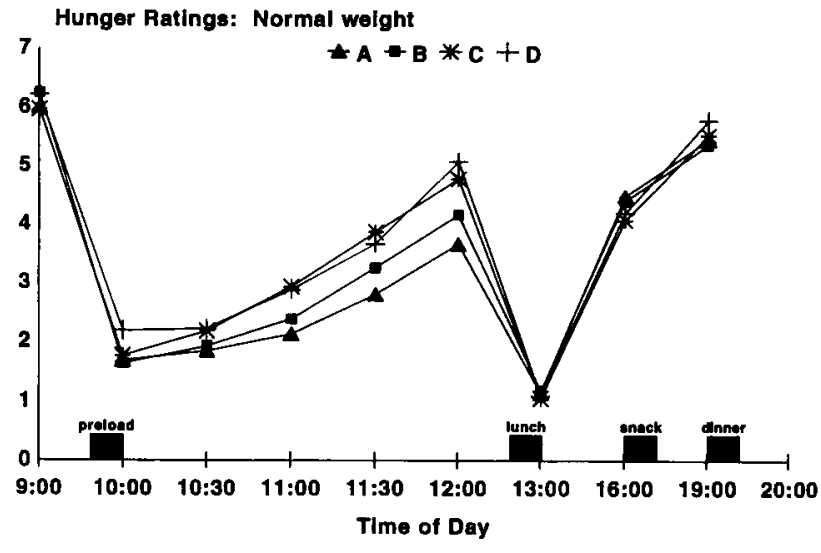

Figure 1. Hunger ratings as a function of preload type at different times postingestion. Preload types are A, sucrose $(700 \mathrm{kcal}) ; \mathrm{B}$, aspartame and maltodextrin (700 $\mathrm{kcal})$; C, aspartame (300 kcal); and D, plain (300 kcal). Reprinted with permission from Drewnowski A, Massien C, Louis-Sylvestre J, et al. Am J Clin Nutr 1991;53: $1159-64$.

than by its sweetness or caloric density. In that study, $560 \mathrm{~mL}$ of carbonated mineral water reduced motivational ratings (desire to eat) more effectively than $280 \mathrm{~mL}$ of mineral water. In contrast, there was no difference between $560 \mathrm{~mL}$ of mineral water and $560 \mathrm{~mL}$ of aspartame-sweetened diet soda. It may be that subjective ratings of hunger and satiety are simply not a sensitive enough measure of acute changes in energy status. For example, two preloads differing by only $80 \mathrm{kcal}$ administered 3 hours following a $400 \mathrm{kcal}$ breakfast are unlikely to lead to major shifts in hunger ratings as measured 15 and 45 minutes postingestion.?

A reasonable question is then: at what point do subjects become aware of the difference between low-energy and high-energy preloads? One recent study ${ }^{8}$ tracked the desire to eat with time as a function of preload type. That study compared the effects of four breakfast preloads on motivational ratings and energy intakes of 24 normal-weight men and women. The preloads, composed of creamy white cheese, were either plain or sweetened with aspartame or sucrose. While all preloads were of comparable volume $(500 \mathrm{~mL})$, the difference in energy value between the low- and high-energy preloads was $400 \mathrm{kcal}$. Motivational ratings were obtained at 30-minute intervals for up to 120 minutes. These data are summarized in Figure 1.

All four preloads initially suppressed hunger ratings to a comparable extent. This observation is consistent with prior findings that aspartame- and sucrose-sweetened beverages had similar effects on hunger ratings, at least immediately postingestion. ${ }^{3}$ However, hunger ratings measured during the subsequent 2 hours clearly showed that the consump- 


\begin{tabular}{|c|c|c|c|c|c|c|}
\hline Study & Subjects & $\begin{array}{l}\text { Dose } \\
(\mathrm{mg})\end{array}$ & Vehicle & Test Meal & Hunger Ratings & Food Intake \\
\hline Black et al. ${ }^{15}$ & 20 men & 170 & $\begin{array}{l}288 \mathrm{~mL}, 560 \\
\mathrm{~mL} \text { soft } \\
\text { drink }\end{array}$ & $\begin{array}{l}\text { Lunch, 60-minute } \\
\text { delay }\end{array}$ & $\begin{array}{l}\text { No effect compared } \\
\text { with mineral water }\end{array}$ & $\begin{array}{l}\text { No effect compared } \\
\text { with mineral water }\end{array}$ \\
\hline Black et al. ${ }^{6}$ & 18 men & 340 & $\begin{array}{l}280 \mathrm{~mL}, 560 \\
\mathrm{~mL} \text { soft } \\
\text { drink }\end{array}$ & $\begin{array}{l}\text { Lunch, 60-minute } \\
\text { delay }\end{array}$ & $\begin{array}{l}\text { No effect compared } \\
\text { with } 560 \mathrm{~mL} \text { miner- } \\
\text { al water; increased } \\
\text { compared with } 280 \\
\text { mL mineral water }\end{array}$ & $\begin{array}{l}\text { No effect compared } \\
\text { with mineral water }\end{array}$ \\
\hline Canty and Chan ${ }^{7}$ & $\begin{array}{l}18 \text { women } \\
2 \text { men }\end{array}$ & 112 & $\begin{array}{l}200 \mathrm{~mL} \text { soft } \\
\text { drink }\end{array}$ & $\begin{array}{l}\text { Lunch. } 60 \text {-minute } \\
\text { delay }\end{array}$ & $\begin{array}{l}\text { No effect compared } \\
\text { with water }\end{array}$ & $\begin{array}{l}\text { No effect compared } \\
\text { with water }\end{array}$ \\
\hline Drewnowski et al. ${ }^{8}$ & $\begin{array}{l}12 \text { men } \\
12 \text { women }\end{array}$ & 500 & $\begin{array}{l}500 \mathrm{~mL} \\
\text { fromage } \\
\text { blanc }\end{array}$ & $\begin{array}{l}\text { Lunch, 3-hour de- } \\
\text { lay } \\
\text { Snack, 6.5-hour de- } \\
\text { lay } \\
\text { Dinner, 9.5-hour } \\
\text { delay }\end{array}$ & $\begin{array}{l}\text { No effect compared } \\
\text { with plain preload }\end{array}$ & $\begin{array}{l}\text { No effect compared } \\
\text { with plain preload }\end{array}$ \\
\hline Drewnowski et al. ${ }^{9}$ & $\begin{array}{l}12 \text { obese } \\
12 \text { lean } \\
\text { women }\end{array}$ & 500 & $\begin{array}{l}500 \mathrm{~mL} \\
\text { fromage } \\
\text { blanc }\end{array}$ & $\begin{array}{l}\text { Lunch, 3-hour de- } \\
\text { lay } \\
\text { Snack, 6.5-hour de- } \\
\text { lay } \\
\text { Dinner, 9.5-hour } \\
\text { delay }\end{array}$ & $\begin{array}{l}\text { No effect compared } \\
\text { with plain preload }\end{array}$ & $\begin{array}{l}\text { No effect compared } \\
\text { with plain preload }\end{array}$ \\
\hline
\end{tabular}

tion of lower-energy breakfasts $(300 \mathrm{kcal}$ versus $700 \mathrm{kcal})$ led to increased hunger ratings by noon. While reducing calories in the substitution condition may initially pass unnoticed, caloric deficit will be eventually associated with greater hunger. If the time period between a preload and the test meal is 60 minutes or less, this effect is likely to be missed.

While the hunger ratings shown in Figure 1 clearly varied with the energy content of breakfast preloads, they were not affected by sweet taste. Identical temporal profiles were obtained for aspartame-sweetened and plain breakfast preloads, and there was no suggestion that the addition of sweet taste to a plain stimulus promoted hunger or the desire to eat.

\section{Do Intense Sweeteners Increase Food Consumption?}

The single report ${ }^{11}$ that one saccharin-sweetened yogurt led to increased food consumption throughout the day has not been replicated in any of the later studies. Using plain and aspartame-sweetened but equicaloric cereals, Mattes ${ }^{26}$ failed to find an appetite-stimulating effect of sweet taste. In another study, ${ }^{6}$ the consumption of an aspartame-sweetened soft drink ( $280 \mathrm{~mL}$ or $560 \mathrm{~mL}$ ) as opposed to mineral water did not lead to increased food consumption at lunch 60 minutes later.

In our studies, ${ }^{8.9}$ the consumption of a plain ver- sus aspartame-sweetened "fromage blanc" at breakfast did not influence energy intakes at lunch (3-hour delay), snack (6.5-hour delay), or dinner (9.5-hour delay) (Table 1). There is simply no evidence that the addition of sweet taste to a plain preload promotes food consumption either at the next meal or at another point during the day.

The issue of caloric compensation following the substitution of sucrose with low-energy intense sweeteners is another matter. Published studies have variously reported perfect compensation, partial compensation, or no compensation at all. For example, Rogers and Blundell ${ }^{11}$ observed that the ingestion of saccharine-sweetened $(131 \mathrm{kcal})$ as opposed to glucose-sweetened yogurt $(295 \mathrm{kcal})$ resulted in perfect calorie compensation in a meal presented 60 minutes later. Similarly, Birch et al..$^{14}$ observed perfect calorie compensation among 2-5year-old children following intense sweetener preloads. However, while young children ate more food following an aspartame-sweetened than sucrosesweetened soft drink, a similar study conducted with 9-10-year-old children ${ }^{13}$ showed no energy compensation at all.

Perfect compensation was observed in a longerterm residential study, conducted with six normalweight, nondieting males. ${ }^{28}$ In that study, the carbohydrate content of lunch was reduced by $400 \mathrm{kcal}$ for 3 days. Most of this dietary manipulation was due to the substitution of aspartame for sugar. The 
subjects made up for the caloric deficit every day of the experiment, and this difference was seen by dinnertime. ${ }^{28}$ Reducing the energy content of lunches did not result in a lower energy intake at the end of the day.

However, different experimental conditions have led to findings of partial compensation or no compensation at all. In one study, ${ }^{20}$ men and women given low- or high-calorie versions of a pudding or gelatin dessert showed no compensation, consuming the same amount of food at a buffet lunch presented 2 hours later. Although there was a trend to consume slightly more calories at lunch following the low-calorie preload, the difference between conditions was not statistically significant. In another study, ${ }^{17}$ lemonade preloads sweetened with aspartame as opposed to sucrose led to energy compensation when the meal was presented 30 or 60 minutes after the preload, but not when the preload and the lunch were consumed at the same time.

Other studies suggest that when compensation occurs, it is only partial. In a recent study that did not involve intense sweeteners, ${ }^{29} 18$ young men were presented with low- and high-energy lunches (538 kcal versus $952 \mathrm{kcal})$. Test snacks high in carbohydrate or fat were presented 2 hours later. While all subjects consumed more of the high-fat than the high-carbohydrate snacks, the amount of energy compensation for a $400-\mathrm{kcal}$ deficit ranged from 186 to $313 \mathrm{kcal}$. In our study of normal-weight men and women, ${ }^{8}$ a $400-\mathrm{kcal}$ deficit at breakfast time led to a slightly greater energy intake at lunch (111 kcal). However, no further energy compensation was observed at later meals, and the total food consumption at meals was independent of the amount of energy consumed at breakfast time. In this way, low-energy breakfasts did result in a lower energy intake by the end of the day. These data, summarized in Figure 2, are consistent with a prior study by de Graaf et al. ${ }^{30}$ but contrast with the finding of perfect compensation obtained after a lunchtime preload. ${ }^{28}$

The presence or absence of energy compensation may well depend on the experimental methods. The nature of the preload (liquid or solid), its timing (breakfast or lunch), and the time interval between preload and the test meal may all be important factors. In addition, the extent of energy compensation may well be influenced by the subjects' sex and age, their habitual diet, and the degree of dietary restraint. Rolls and colleagues ${ }^{31}$ reported near perfect energy compensation for a group of non dieting young men, but variable results with a group of restrained women. It may be that nonrestrained young men are more likely to show compensatory behavior than are older and overweight women. More studies ought to be conducted with the latter pop-

\section{Energy intake at meals}

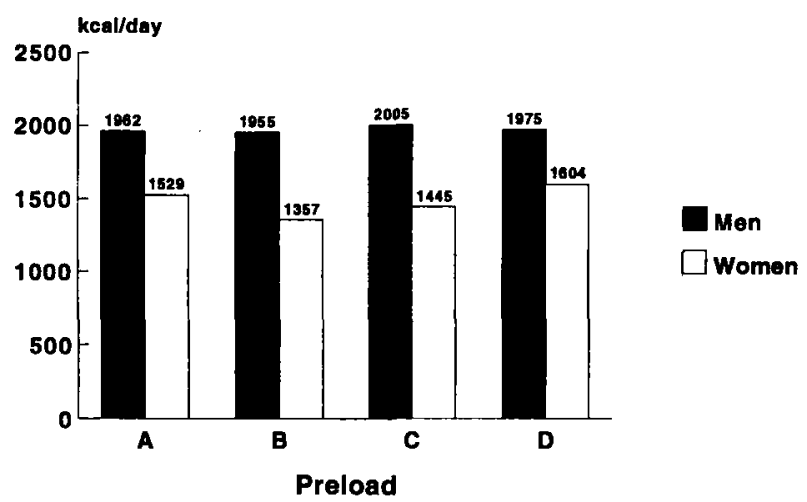

Figure 2. Daily energy intakes at meals (excluding preload) as a function of preload type. Preload types are A, sucrose $(700 \mathrm{kcal}) ; \mathrm{B}$, aspartame and maltodextrin (700 kcal); C, aspartame (300 kcal); and D, plain (300 kcal). Reprinted with permission from Drewnowski A, Massien C, Louis-Sylvestre J, et al. Am J Clin Nutr 1991;53: 1159-64.

ulation, since data obtained with young college subjects are not necessarily applicable to the adult population at large.

\section{Is There Physiological Adaptation to Intense Sweeteners?}

Studies on intense sweeteners and appetite have focused on food consumption at the next meal or snack. However, longer-term studies are needed to explore chronic effects of intense sweeteners on food consumption and body weight. One concern, voiced by several researchers, ${ }^{32,33}$ is that users of intense sweeteners may gradually learn to compensate for the calories missing from their diets. In one view, ${ }^{33}$ compensation is expected to become more accurate as the consumer learns about the postingestive, satiating effects of a food.

Is energy compensation a learned phenomenon? Only a few long-term studies are available to answer this question. In an early clinical study by Porikos et al., ${ }^{34}$ replacing sucrose with aspartame over a period of 11 days led to only a partial $(40 \%)$ compensation for the missing sucrose calories. In another study, ${ }^{35}$ the consumption of $1135 \mathrm{~mL}$ of aspartame-sweetened as opposed to fructose-sweetened soft drink daily for 21 days was associated with lower energy intakes. The calorie savings derived not from a reduction in food intake but from a decline in habitual soft drink consumption, that is sugar calories. Statistics from USDA further suggest that consumers have not replaced sugar in soft drinks with sugar from other sources. In other words, the provision of noncaloric sweet taste may well prevent increased consumption of other sweets. 


\section{Do Intense Sweeteners Help with Weight Reduction?}

The impact of intense sweeteners on the diet of the general population is difficult to assess, since there are no data on how many people might become overweight if low-calorie foods were not available. Noncaloric soft drinks are widely used by dieters, not all of whom are overweight, and are widely regarded as a valuable tool in weight control.

The available clinical data are extremely limited. Following a previous report ${ }^{36}$ that female users of aspartame-sweetened foods lost more weight than nonusers in a 12-week weight loss program, only one study ${ }^{37}$ examined the effects of aspartame on the long-term control of body weight.

In that study, 163 obese women clients of a multidisciplinary weight control program were randomly assigned to one of two groups. They were asked either to consume or to abstain from aspartamesweetened foods and beverages during the active weight loss (19 weeks) and during the follow-up phase (2.5 years). While the initial weight loss was comparable for the two groups, the sweetener group showed better weight maintenance during the follow-up period. The authors interpret these data as providing evidence that aspartame improved compliance and, together with reduced-calorie diet and exercise, facilitated long-term control of body weight.

\section{New Horizons for Research}

Most studies on intense sweeteners and appetite have been conducted with children and college students. There is a need for additional studies with adult women, who are the principal users of diet products. Greater emphasis should also be placed on long-term as opposed to acute studies.

There is a further need for studies on diet satisfaction and dietary compliance. Since intense sweeteners are not appetite suppressants, their chief use may be in extending the range of palatable but low-calorie foods and promoting adherence to a low-calorie diet. ${ }^{38}$

1. Blundell J, Hill AJ. Paradoxical effects of an intense sweetener (aspartame) on appetite. The Lancet 1986;1:1092-3

2. Rogers PJ. Appetite control and the use of intense sweeteners. Nutr \& Food Sci 1993;6:13-5

3. Rolls BJ. Effect of intense sweeteners on hunger, food intake and body weight: a review. Am J Clin Nutr 1991;53:872-8

4. Rogers PJ, Blundell JE. Intense sweeteners and appetite. Am J Clin Nutr 1993;58:120-1

5. Rolls BJ. Reply to PJ Rogers and JE Blundeil. Am J Clin Nutr 1993;58:121-2
6. Black RM, Leiter LA, Anderson GH. Consuming aspartame with and without taste: differential effects on appetite and food intake of young adult males. Physiol Behav 1993;53:459-66

7. Canty DJ, Chan MM. Effects of consumption of caloric vs noncaloric sweet drinks on indices of hunger and food consumption in normal adults. Am $\mathrm{J}$ Clin Nutr 1991;53:1159-64

8. Drewnowski A, Massien C, Louis-Sylvestre J, Fricker $\mathrm{J}$, Chapelot D, Apfelbaum M. Comparing the effects of aspartame and sucrose on motivational ratings, taste preferences, and energy intakes in humans. Am J Clin Nutr 1994;59:338-45

9. Drewnowski A, Massien C, Louis-Sylvestre J, Fricker J, Chapelot D, Apfelbaum M. The effects of aspartame versus sucrose on motivational ratings, taste preferences, and energy intakes in obese and lean women. Int J Obesity 1994;18:570-8

10. Blundell JE, Hill AJ. Artificial sweeteners and the control of appetite: implications for the eating disorders. In: Worden D, Parke D, Marks J, eds. The future of predictive safety evaluations. MTP Press, 1987;2: 263-8

11. Rogers PJ, Blundell JE. Separating the actions of sweetness and calories: effects of saccharin and carbohydrates on hunger and food intake in human subjects. Physiol Behav 1989;45:1093-9

12. Renwick $A G$. Intense sweeteners, food intake, and the weight of a body of evidence. Physiol Behav 1994;55:139-43

13. Anderson GH, Savaris $S$, Schacher $S$, Zlotkin S, Leiter LA. Aspartame: effect on lunch-time food intake, appetite and hedonic response in children. Appetite 1989;13:93-103

14. Birch LL, McPhee L, Sullivan S. Children's food intake following drinks sweetened with sucrose or aspartame: time course effects. Physiol Behav 1989;45:387-95

15. Black RM, Tanaka PA, Leiter LA, Anderson GH. Soft drinks with aspartame: effect on subjective hunger, food selection and food intake in young adult males. Physiol Behav 1991;49:803-10

16. Rodin J. Comparative effects of fructose, aspartame, glucose, and water preloads on calorie and macronutrient intake. Am J Clin Nutr 1990;51:428-35

17. Rolls BJ, Kim S, Fedoroff IC. Effects of drinks sweetened with sucrose or aspartame on hunger, thirst and food intake in men. Physiol Behav 1990;48:1926

18. Mattes R. Effects of aspartame and sucrose on hunger and energy intake in humans. Physiol Behav 1990;47:1037-44

19. Rolls BJ, Hetherington M, Laster LJ. Comparison of the effects of aspartame and sucrose on appetite and food intake. Appetite 1988;11(suppl 1):62-7

20. Rolls BJ, Laster LJ, Summerfelt A. Hunger and food intake following consumption of low-calorie foods. Appetite 1989;13:115-27

21. Blundell JE, Rogers PJ, Hill AJ. Uncoupling sweetness and calories: methodological aspects of laboratory studies on appetite control. Appetite 1988;11(suppl 1):54-61 
22. Rogers PJ, Carlyle J, Hill AJ, Blundell JE. Uncoupling sweet taste and calories: comparison of the effects of glucose and three intense sweeteners on hunger and food intake. Physiol Behav 1988;43:547-52

23. Drewnowski A, Greenwood MRC. Cream and sugar: human preferences for high-fat foods. Physiol Behav 1983;30:629-33

24. Wooley OW, Wooley SC, Dunham RB. Calories and sweet taste: effects on sucrose preference in the obese and nonobese. Physiol Behav 1972;9:765-8

25. Rolls BJ. Sweetness and satiety. In: Dobbing J (ed). Sweetness. Berlin: Springer-Verlag, 1987:161-72

26. Mattes RE. Hunger ratings are not a valid proxy measure of reported food intake in humans. Appetite 1990;15:103-13

27. Tordoff MG, Alleva AM. Oral stimulation with aspartame increases hunger. Physiol Behav 1990;47 555-9

28. Foltin RW, Fischman MW, Moran TH, Rolls BJ, Kelly TH. Caloric compensation for lunches varying in fat and carbohydrate content by humans in a residential laboratory. Am J Clin Nutr 1990;52:969-80

29. Green SM, Burley VJ, Blundell JE. Effect of fat- and sucrose-containing foods on the size of eating episodes and energy intake in lean males: potential for causing overconsumption. Eur J Clin Nutr 1994;48: 547-55

30. De Graaf C, Hulshof T, Weststrate JA, Jas P. Shortterm effects of different amounts of protein, fats, and carbohydrates on satiety. Am J Clin Nutr 1992;55: 33-8

31. Rolls BJ, Kim-Harris S, Fischman MW, et al. Satiety after preloads with different amounts of fat and carbohydrate: implications for obesity. Am J Clin Nutr 1994;60:476-87

32. Bellisle F, Perez C. Low-energy substitutes for sugars and fats in the human diet: impact on nutritional regulation. Neurosci Biobehav Rev 1994;18:197-205

33. Louis-Sylvestre J, Tournier A, Verger P, Chabert M, Delorme B. Learned caloric adjustment of human intake. Appetite 1989;12:95-103

34. Porikos KP, Hesser MF, Van Itallie TB. Calorie regulation in normal-weight men maintained on a palatable diet of conventional food. Physiol Behav 1982;29:293-300

35. Tordoff MG, Alleva AM. Effect of drinking soda sweetened with aspartame or high-fructose corn syrup on food intake and body weight. Am J Clin Nutr 1990;51:963-9

36. Kanders BS, Lavin PT, Kowalchuk MB, Greenberg I, Blackburn GL. An evaluation of the effect of aspartame on weight loss. Appetite 1988;11(suppl 1):7384

37. Kanders BS, Blackburn G, Lavin P, Joy P, Folan A. Long-term ( 3 year) control of body weight: effect of aspartame. Obesity Res 1993;1(suppl 1):114S

38. Drewnowski A. Low-calorie foods and the prevalence of obesity. In: AM Altschul, ed. Low-calorie foods handbook. New York: Marcel Dekker, 1993:513-34 